\title{
ÉPOCA, LOCAL DE COLHEITA E ARMAZENAMENTO NA QUALIDADE FISIOLÓGICA DA SEMENTE DE SEMPRE-VIVA (Syngonanthus elegans (Bong.) Ruhland - ERIOCAULACEAE) ${ }^{1}$
}

\author{
SILVIA CRISTINA PASLAUSKI NUNES², UBIRAJARA RUSSI NUNES ${ }^{3}$, PATRÍCIA GOMES FONSECA², \\ PAULO HENRIQUE GRAZZIOTTI' ${ }^{3}$ ROGÉRIO GOMES PEGO ${ }^{4}$, LEANDRO MARCIANO MARRA ${ }^{4}$
}

\begin{abstract}
RESUMO - O objetivo deste trabalho foi avaliar a qualidade fisiológica de sementes da sempreviva (Syngonanthus elegans (Bong.) Ruhland) colhidas em diferentes épocas e locais e submetidas ao armazenamento. Capítulos de S. elegans foram colhidos em duas áreas de ocorrência natural no Campus II da Universidade Federal dos Vales do Jequitinhonha e Mucuri - UFVJM, em Diamantina, MG, em um Neossolo Quartzarênico Órtico típico (local 1) e Neossolo Quartzarênico Hidromórfico típico (local 2), em cinco épocas (04/07/05, 19/07/05, 22/08/05, 21/09/05 e 20/10/05) e, posteriormente, submetidos a testes para avaliação do vigor e da germinação da semente (Experimento 1). Os capítulos colhidos em 04/07/05 (locais 1 e 2) foram acondicionados em sacos de polietileno transparente e armazenados no Laboratório de Sementes em temperatura ambiente $\left(20^{\circ} \pm 2^{\circ} \mathrm{C}\right)$ ou em geladeira $\left(5^{\circ} \pm 2^{\circ} \mathrm{C}\right)$, por zero, quatro, oito e 12 meses. Após esses períodos, as sementes foram novamente avaliadas quanto ao vigor e à germinação (Experimento 2). O delineamento experimental foi o inteiramente casualizado, no esquema fatorial $5 \times 2$ (época $\mathrm{x}$ local de colheita) para o Experimento 1 ; e o esquema fatorial $4 \times 2 \times 2$ (armazenamento $\mathrm{x}$ local de colheita $\mathrm{x}$ temperatura de armazenamento) para o Experimento 2, com quatro repetições. A qualidade fisiológica da semente de S. elegans variou em função da época e do local de colheita. Durante o armazenamento, o vigor e a germinação não variaram com o local de colheita e a temperatura de armazenamento. $\mathrm{O}$ armazenamento por 12 meses em geladeira ou temperatura ambiente melhorou a qualidade fisiológica da semente.
\end{abstract}

Termos para indexação: temperatura, vigor, germinação.

\section{INFLUENCE OF TIME OF HARVEST, LOCATION OF PRODUCTION, AND STORAGE ON THE PHYSIOLOGICAL QUALITY OF SEEDS OF STAR-FLOWERS (Syngonanthus elegans} (Bong.) Ruhland - ERIOCAULACEAE)

\begin{abstract}
The objective of this study was to evaluate the physiological quality of star-flower (Syngonanthus elegans (Bong.) Ruhland) seeds produced at different locations, harvested at different times and then stored under different conditions and for different periods of time. Capitula of $S$. elegans were colected in two areas of star-flowers plants natural occurrence on the Campus II of the Federal University of the Valleys of Jequitinhonha and Mucuri, in Diamantina, state of Minas Gerais, Brazil, in a typical Orthic Quartzarenicenic Neossoil (location 1) and a typical Hydromorphic Quartzarenic Neossoil (location 2) at 07/04/05, 07/19/05, 08/22/05, 09/21/05, and 10/20/05) and later
\end{abstract}

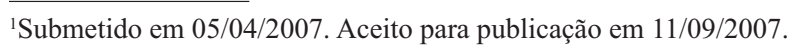

${ }^{2}$ Mestrandas do Programa de Pós-Graduação em Produção Vegetal, Departamento de Agronomia - UFVJM, 39100-000. Diamantina, MG.; e-mail: spaslauski@yahoo.com.br; path2233@yahoo.com.br

${ }^{3}$ Eng. Agr ${ }^{\circ}$, D.S., Prof. Adjunto, Departamento de Agronomia - UFVJM,
39100-000. Diamantina, MG.; e-mail: russinunes@yahoo.com.br; grazziot@yahoo.com.br

${ }^{4}$ Alunos de Graduação do Curso de Agronomia-UFVJM,39100-000, Diamantina, MG.; e-mail: engagropego@yahoo.com.br; lmarciano3@hotmail.com 
submitted to germination and vigor tests (Experiment 1). The capitula taken on 07/04/05 (locations 1 and 2) were placed in transparent polyethylene bags and stored either in a seed laboratory at room temperature $\left(20 \pm 2^{\circ} \mathrm{C}\right)$ or in a refrigerator $\left(5 \pm 2^{\circ} \mathrm{C}\right)$, for zero, four, eight, and 12 months. After these periods, the seeds were evaluated again for germination and vigor (Experiment 2). A completely random design in a $2 \times 5$ factorial was used (harvest time and production location) for Experiment 1; and a $4 \times 2 \times 2$ factorial scheme (storage time $\mathrm{x}$ location $\mathrm{x}$ storage temperature) for Experiment 2, with four replications. The physiological quality of $S$. elegans seeds varied in function of time and location of production. During storage, germination and vigor did not vary with production location and storage temperature. Storage for 12 months in a refrigerator or at room temperature resulted in higher percentages of normally germinating seeds.

Index terms: temperature, vigor, germination.

\section{INTRODUÇÃO}

Syngonanthus elegans (Bong.) Ruhland pertence à família Eriocaulaceae e ocorre naturalmente no Brasil, nos Campos Rupestres, principalmente na região de Diamantina, MG, fazendo parte da Cadeia do Espinhaço que se estende nos estados de Minas Gerais e Bahia (Scatena et al., 1996).

A colheita de $S$. elegans, conhecida popularmente como "sempre-viva", pé-de-ouro, constitui-se em importante atividade econômica para a população da região. As flores dessa espécie, após serem colhidas, conservam a cor e a forma por um período mais longo de tempo, o que lhes confere alto valor comercial, principalmente no mercado internacional (Giulietti et al., 1988).

Devido ao extrativismo desordenado, sem considerar questões ecológicas e de manejo cultural, espécies de sempre-vivas estão sendo extintas de seu ambiente natural (Mendonça e Lins, 2000) e colocando em risco a diversidade da flora, podendo resultar no encerramento dessa atividade.

A preservação de espécies florestais em bancos de germoplasma, necessariamente passa pelo conhecimento da ecofisiologia e do comportamento da semente sob armazenamento. Assim, a interação da umidade e da temperatura (Biancheti, 1981), a idade e a condição de cultivo (Tole, 1973), a influência das características genéticas, a sensibilidade à luz e a germinação iniciais da semente são fatores fundamentais na manutenção da qualidade fisiológica da semente durante o armazenamento (Carneiro e Aguiar, 1993; Aguiar, 1995).

Entretanto, não há informações sobre o comportamento de armazenamento da semente de $S$. elegans, o que ressalta a necessidade de estudos mais detalhados para essa espécie.

O objetivo desta pesquisa foi avaliar a influência da época e do local de colheita e do armazenamento na qualidade fisiológica da semente da sempre-viva S. elegans.

\section{MATERIAL E MÉTODOS}

Experimento 1 - Épocas e locais de colheita. Capítulos de $S$. elegans foram colhidos manualmente em cinco épocas (04/07/05, 19/07/05, 22/08/05, 21/09/05 e 20/10/05), em parcelas de $500 \mathrm{~m}^{2}$, em duas áreas (locais de colheita) de ocorrência natural no Campus II da Universidade Federal dos Vales do Jequitinhonha e Mucuri - UFVJM, em Diamantina,

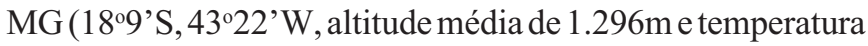
média anual de $18,1^{\circ} \mathrm{C}$ ). Os dados de temperatura média e precipitação pluviométrica, referentes ao período do trabalho e as médias de precipitação pluviométrica, entre 1971 a 1990, foram coletados na Estação Meteorológica de Diamantina (INMET, 2006) e se encontram na Figura 1. O local 1 encontra-se em um Neossolo Quartzarênico Órtico típico, textura arenosa, extremamente drenado, ácido, com baixos teores de matéria orgânica e de nutrientes $\left(\mathrm{Ca}^{2+}, \mathrm{Mg}^{2+}, \mathrm{K}^{+}\right.$e P), baixa Capacidade de Troca Catiônica (CTC), com elevados teores de $\mathrm{Al}^{3+}$ e situa-se próximo ao Córrego Soberbo que corta o Campus. Essa área não possui afloramento de rochas e o solo apresenta-se bem drenado. O local 2 é formado por um Neossolo Quartzarênico Hidromórfico Típico, textura arenosa, ácido, com médios teores de matéria orgânica e baixos valores de nutrientes, baixa CTC, com significativos teores de $\mathrm{Al}^{3+}$. O relevo plano condiciona o acúmulo de água no solo por grande parte do ano (Embrapa, 2006). Situa-se próxima à Rodovia BR 367, apresentando afloramento de rochas, constantemente úmido e distante, aproximadamente, a $1.000 \mathrm{~m}$ do local 1. Após a colheita, os capítulos foram secados à temperatura ambiente no Laboratório de Sementes (LS) da UFVJM, até apresentar grau de umidade entre $10 \%$ e $11 \%$ (base úmida). As sementes foram extraídas pela leve fricção dos capítulos com uma espátula sobre placas de Petri, sendo separadas, posteriormente, com o auxílio do microscópio estereoscópico. Em seqüência, cada amostra de semente, correspondendo às 


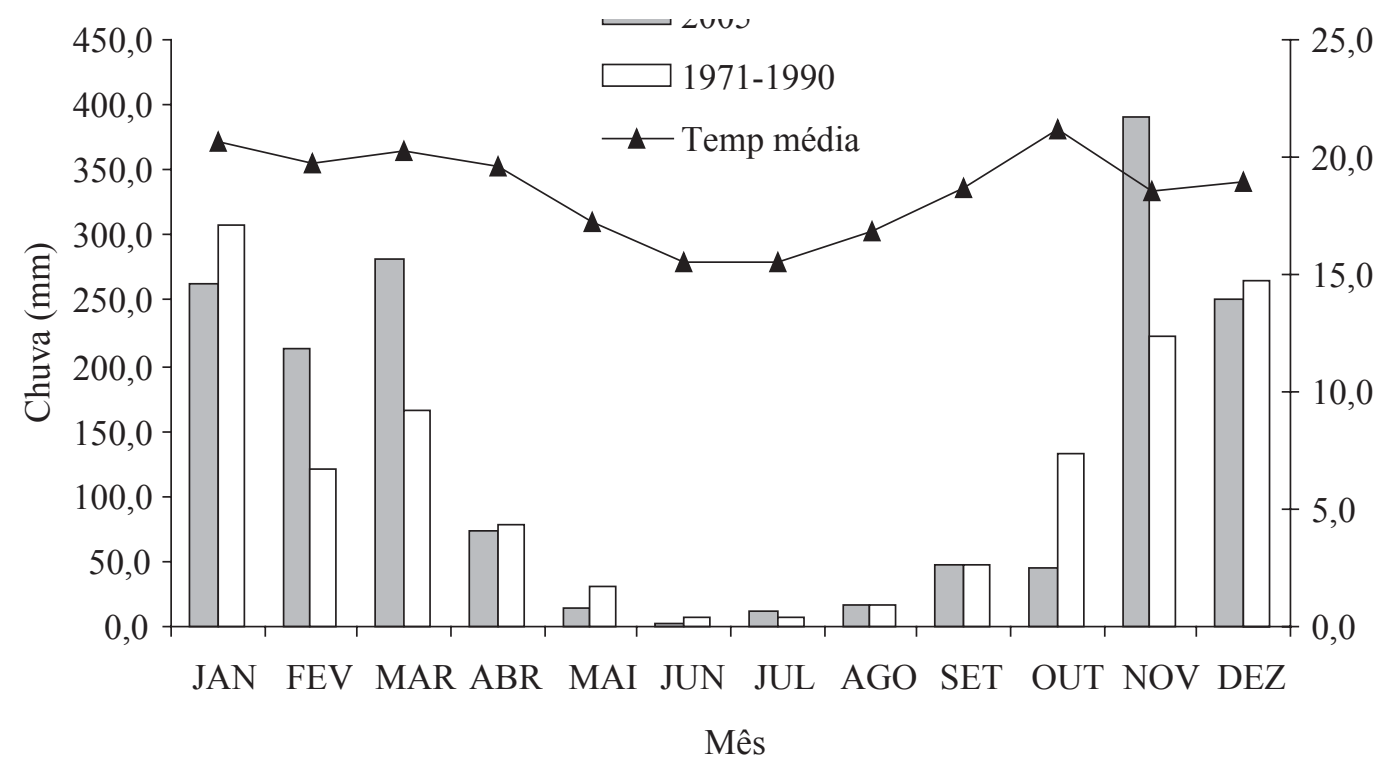

FIGURA 1. Distribuição mensal da precipitação (2005 e de 1971 a 1990) e temperatura média durante o período de estudo em Diamantina, MG.

épocas e aos locais de colheita, foi submetida aos testes de vigor e germinação, utilizando-se a metodologia proposta por Kraus et al. (1996) adaptada: 100 sementes foram colocadas em placas de Petri (quatro repetições de 25 sementes), forradas com papel filtro umedecido com água destilada, com peso equivalente a três vezes o peso do papel seco, e ensacadas com sacos transparentes de polietileno. Em seguida, as placas de Petri foram colocadas em câmara de germinação com 24 horas de luz por dia $\left(30 \mu \mathrm{mol} \cdot \mathrm{m}^{-2} \cdot \mathrm{s}^{-1}\right.$ de iluminância) a $25^{\circ} \mathrm{C}$, por quarenta dias. A germinação foi avaliada, com o uso do microscópio estereoscópico, através da percentagem de plântulas normais, realizadas em duas contagens. A primeira contagem das plântulas foi realizada aos 20 dias e a segunda aos 40 dias do início do teste. Para vigor, foi considerada a percentagem de plântulas normais ocorrida aos 20 dias após o início do teste de germinação.

Experimento 2 - Locais de colheita e armazenamento. Logo após a colheita de 04/07/05, parte dos capítulos (locais 1 e 2) foram acondicionados em sacos de polietileno e armazenados no LS em temperatura ambiente $\left(20^{\circ} \pm 2^{\circ} \mathrm{C}\right)$ e em geladeira $\left(5^{\circ} \pm 2^{\circ} \mathrm{C}\right)$ por zero, quatro, oito e 12 meses. Após cada período de armazenamento (temperatura ambiente e geladeira), as sementes foram extraídas dos capítulos com uma espátula sobre placas de Petri sendo separadas, posteriormente, com o auxílio de microscópio estereoscópico. Para avaliação do vigor e da germinação, foram realizados os mesmos procedimentos relatados anteriormente, no ambiente de laboratório e na geladeira; o grau de umidade das sementes manteve-se entre $10 \%$ e $11 \%$, durante o período de armazenamento.

$\mathrm{O}$ delineamento experimental foi $\mathrm{o}$ inteiramente casualizado, no esquema fatorial $5 \times 2$ (época $\mathrm{x}$ local de colheita) para o Experimentol e o esquema fatorial $4 \times 2 \times 2$ (armazenamento $\times$ local de colheita $\times$ temperatura de armazenamento) para o Experimento 2, com quatro repetições. Os dados de vigor e de germinação foram previamente transformados em arco-seno $\sqrt{\% / 100}$, para análise estatística. As comparações entre as médias foram feitas mediante a aplicação do teste de Tukey, ao nível de $5 \%$ de probabilidade.

\section{RESULTADOS E DISCUSSÃO}

Experimento 1 - Épocas e locais de colheita. Os resultados obtidos no teste de vigor e germinação para os locais 1 e 2 , nas diferentes épocas de colheita, encontram-se na Tabela 1. Houve diferença estatística significativa entre locais e épocas de colheita, com respostas variadas para vigor e germinação. Os maiores valores de vigor (35\% e 17\%) foram obtidos quando a colheita das sementes foi em 20/10/05, no local 1, e em 19/07/05, no local 2. Na colheita realizada em 20/10/05, no local 1 , os valores de vigor superaram os obtidos no local 2. O vigor das sementes, quando colhidas em 19/07/05, no local 2, superou os valores de vigor das sementes colhidas no local 1. 
TABELA 1. Vigor e germinação de semente de Syngonanthus elegans (Bong.) Ruhland, em função das épocas e dos locais de colheita, no ano de 2005.

\begin{tabular}{ccccc}
\hline \multirow{2}{*}{ Época de colheita } & \multicolumn{3}{c}{ Vigor (\%) } & \multicolumn{2}{c}{ Germinação (\%) } \\
\cline { 2 - 5 } & Local 1 & Local 2 & Local 1 & Local 2 \\
\hline $04 / 07 / 05$ & $1,0 \mathrm{Ba}$ & $1,0 \mathrm{Ca}$ & $6,0 \mathrm{Ba}$ & $3,0 \mathrm{Cb}$ \\
$19 / 07 / 05$ & $4,0 \mathrm{Bb}$ & $17,0 \mathrm{Aa}$ & $5,0 \mathrm{Bb}$ & $17,0 \mathrm{Aa}$ \\
$22 / 08 / 05$ & $7,0 \mathrm{Ba}$ & $2,0 \mathrm{BCb}$ & $22,0 \mathrm{Aa}$ & $4,0 \mathrm{Bb}$ \\
$21 / 09 / 05$ & $5,0 \mathrm{Ba}$ & $5,0 \mathrm{Ba}$ & $9,0 \mathrm{Ba}$ & $7,0 \mathrm{Ba}$ \\
$20 / 10 / 05$ & $35,0 \mathrm{Aa}$ & $5,0 \mathrm{Bb}$ & $35,0 \mathrm{Aa}$ & $5,0 \mathrm{Bb}$ \\
\hline $\mathrm{CV}(\%)$ & 4347 & & 3435 & \\
\hline
\end{tabular}

Médias seguidas pelas mesmas letras maiúsculas nas colunas e minúsculas na linha não diferem entre si pelo teste de Tukey, a $5 \%$ de probabilidade.

Para germinação, os maiores valores foram encontrados nas colheitas realizadas em 20/10/05 (35\%) e 22/08/05 (22\%), para o local 1, e em 19/07/05 (17\%), para o local 2. Entre áreas, os maiores valores de germinação foram obtidos em 20/10/05 e 22/08/05 (local 1) e 19/07/05 (local 2). Observa-se que, apesar de os valores de vigor e germinação serem relativamente baixos, no início das colheitas, houve aumento progressivo durante a fase de produção de sementes, para o local 1. Para o local 2, ocorreu o inverso, ou seja, a partir da colheita realizada em 19/07/05, houve decréscimo nesses valores até a última colheita. A diferença na resposta germinativa entre épocas e locais de colheita pode decorrer do fato de que no local $2 \mathrm{o}$ solo apresentava-se constantemente úmido, o que pode ter contribuído para o rápido desenvolvimento das plantas e, com isso, a maturação das sementes ocorreu mais cedo. A partir da colheita realizada em 19/07/05, para o local 2, as sementes perderam a qualidade fisiológica, iniciando o processo de envelhecimento (deterioração).

No local 1, o solo bem drenado não proporcionou boas condições para que as plantas atingissem a maturação mais cedo. Ao contrário, contribuiu para alongar o período de desenvolvimento vegetativo, com as sementes entrando em maturação ao final de outubro. Parra (1998) enfatiza que S. elegans apresenta grandes populações e ampla área de distribuição, desde Diamantina até a Serra do Cipó. Scatena et al. (1999) ponderam que espécies de Syngonanthus crescem em diferentes condições edáficas, habitando solos secos, úmidos e até alagados, sempre expostas ao sol e que esse gênero ocorrendo e produzindo sementes em habitats xéricos, poderia favorecer a germinação da semente sob temperaturas mais elevadas, ou seja, ao final do ciclo de produção (outubro), coincidindo com o início do período das chuvas (local 1). Em áreas com maior propensão ao acúmulo de água no solo, as plantas encontrariam melhores condições para completarem seu ciclo de desenvolvimento. Entretanto, a alta umidade dos solos causa diminuição na amplitude de flutuações térmicas (Klips e Peñalosa, 2003), podendo afetar a resposta germinativa da semente produzida sob tais condições (Oliveira \& Garcia, 2005), o que foi observado no local 2. Considerando a diferença climática e edáfica das áreas de produção de semente de sempre-viva, nos campos rupestres de altitude, presume-se que o período de produção e a qualidade fisiológica da semente varia com o local e durante o ciclo de desenvolvimento. Logo, sugere-se que a distribuição da germinação, no espaço e no tempo, seja uma estratégia dessa espécie, pois, desse modo, a possibilidade de recrutamento das plântulas, ao longo do ciclo de produção, é aumentada.

Experimento 2 - Locais de colheita e armazenamento. A análise estatística dos dados revelou diferença significativa apenas para o fator armazenamento nas características vigor e germinação da semente. Não houve efeito dos fatores local de colheita e temperatura de armazenamento.

Antes do armazenamento, as sementes colhidas em 04/07/05 apresentaram valores médios de vigor de $1 \%$, para os locais 1 e 2 (Tabela 1 e Figura 2). Ao final de 12 meses de armazenamento, os valores médios de vigor foram de $18 \%$ (local 1) e 13,7\% (local 2), representando acréscimo médio de $15 \%$ em relação aos valores iniciais. Entretanto, os valores aos 12 meses de armazenamento não diferiram significativamente dos encontrados aos quatro e oito meses de armazenamento, para os dois locais de colheita (Figura 2).

Para germinação, os valores médios antes do armazenamento foram de 4,5\% (locais 1 e 2). Aos 12 meses de armazenamento foram de $23 \%$ (local 1) e $21 \%$ (local 2), representando acréscimo médio de $18 \%$ para os locais 1 e 2 . Os valores de germinação aos 12 meses de armazenamento 

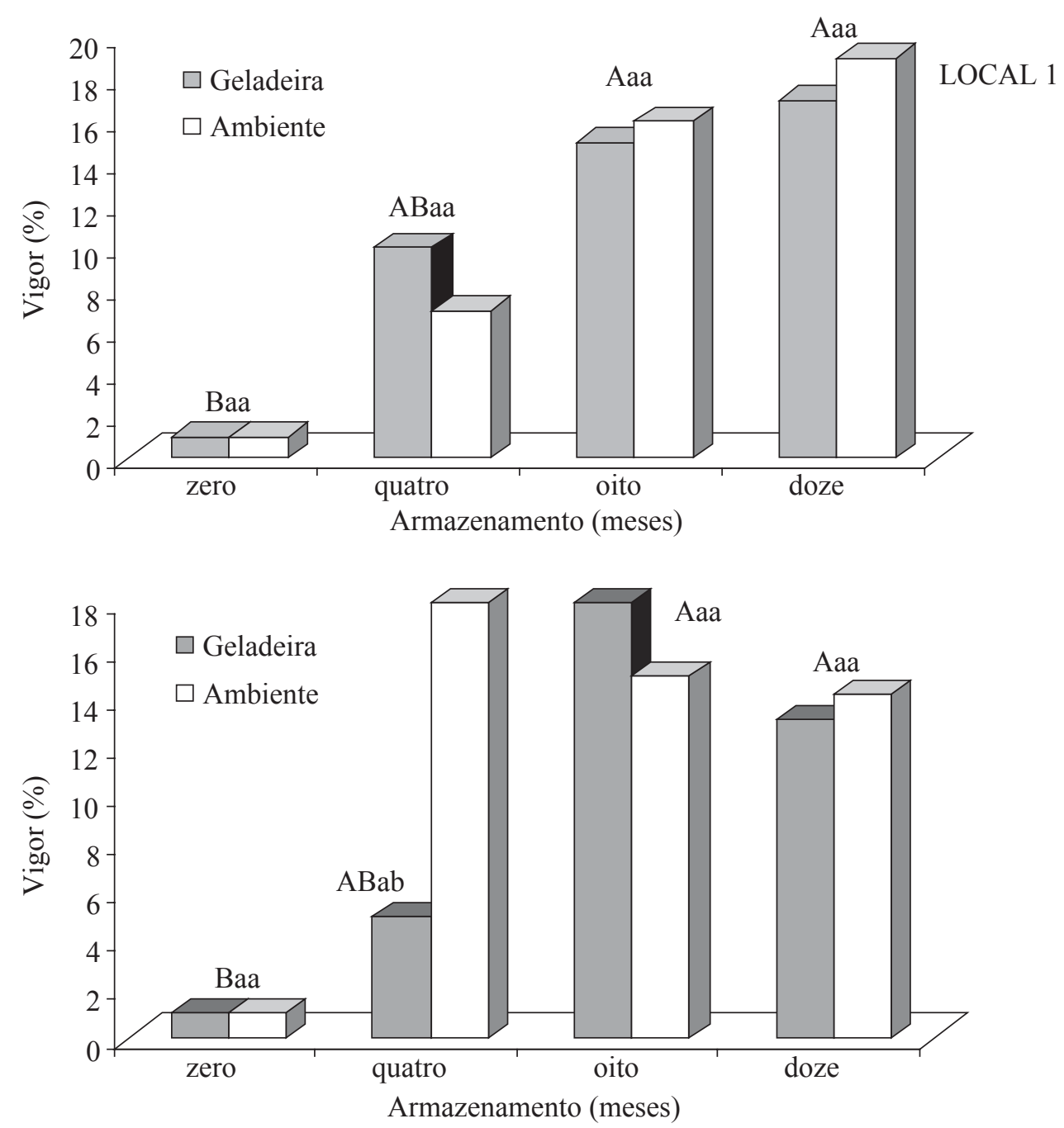

Letras maiúsculas iguais entre os tratamentos de armazenamento e minúsculas entre os tratamentos de temperatura não diferem entre si $(\mathrm{P}<0,05)$, pelo teste de Tukey.

FIGURA 2. Vigor de semente de Syngonanthus elegans (Bong.) Ruhland colhida no local 1 e no local 2, em 04/07/05, em função da temperatura (geladeira e ambiente) e do período de armazenamento.

também não diferiram estatísticamente dos valores encontrados aos quatro e oito meses, para os dois locais de colheita (Figura 3). Oliveira e Garcia (2005) e Scatena et al. (1996), trabalhando com sementes de $S$. elegans, não armazenadas, obtiveram percentagens de germinação de $75 \%$ e $72 \%$, respectivamente, em temperaturas de $30^{\circ}$ e $25^{\circ} \mathrm{C}$. Bedê (2002), em trabalho realizado em São Gonçalo do Rio Preto, MG, obteve taxas de germinação inferiores a $40 \%$, utilizando temperaturas constantes de $15^{\circ}$ a $30^{\circ} \mathrm{C}$. A diferença nos valores de germinação nesses trabalhos e os resultados aqui encontrados pode estar relacionada aos locais e às épocas de colheita das sementes, bem como, às temperaturas utilizadas nos testes. Considerando os maiores valores de vigor e germinação obtidos antes do armazenamento, no Experimento 1 (35\%) para sementes colhidas em 20/10/05 (local 1) e os valores obtidos após o armazenamento no Experimento $2(18 \%$ e $23 \%$ ), para o local 1 , pode-se inferir que o armazenamento por 12 meses em geladeira ou em temperatura ambiente melhorou a qualidade fisiológica da semente.

Os baixos valores de vigor e germinação encontrados antes do armazenamento podem estar relacionados à época em que foi realizada a colheita $(04 / 07 / 05)$, onde as sementes encontravam-se ainda imaturas fisiologicamente, requerendo um período de pós-maturação como sugerem Sá Carvalho e Ribeiro (1994), ou que algum outro mecanismo de impedimento à germinação ainda estivesse presente. Popinigis 

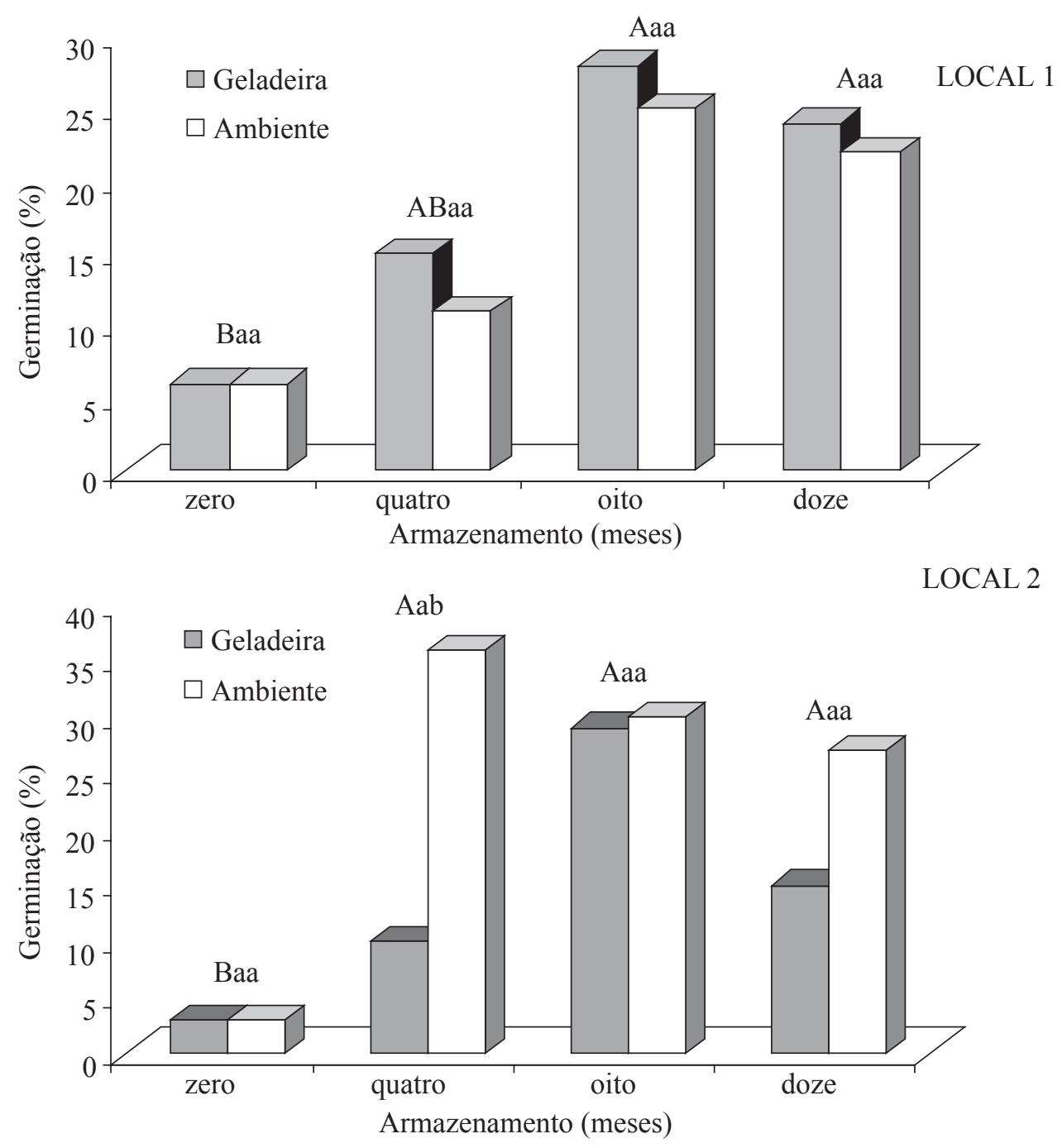

Letras maiúsculas iguais entre os tratamentos de armazenamento e minúsculas entre os tratamentos de temperatura não diferem entre si (P $<0,05)$, pelo teste de Tukey.

FIGURA 3. Germinação de semente de Syngonanthus elegans (Bong.) Ruhland colhida no local 1 e no local 2 , em 04/07/05, em função da temperatura (geladeira e ambiente) e do período de armazenamento.

(1977) descreve a impermeabilidade do tegumento à água e à troca de gases, a presença de inibidores da germinação, a resistência mecânica do tegumento ao crescimento do embrião e a maturidade fisiológica do embrião como causas de dormência encontradas na semente. Com o armazenamento é possível que tais fatores tenham sido total ou parcialmente eliminados. Nakagawa et al. (1999), em trabalho com o azevém-anual, constataram que a semente, com longevidade superior a 10 anos, teve a dormência superada no decorrer do armazenamento. Bewley e Black (1985) enfatizam que, para semente de arroz irrigado, o processo germinativo é impedido pela impossibilidade do embrião absorver oxigênio devido à presença de inibidores da germinação no tegumento. Durante o armazenamento, o consumo de oxigênio pelo tegumento é diminuído e o efeito da dormência é reduzido. Paixão-Santos et al. (2003) relatam que observações da morfologia da semente de $S$. mucugensis Giul. conduzem à idéia da não existência de tegumento endurecido na semente, entretanto, devido à dificuldade de germinação da espécie é provável a existência de uma camada impermeável que impossibilita a embebição.

Essa variação nos valores de vigor e germinação da semente armazenada pode estar relacionada com a estratégia da espécie para a distribuição da capacidade germinativa no tempo, como mencionado anteriormente (Experimento 
1), sendo um modo de sobrevivência da espécie. Soma-se a isso, o fato de que os capítulos foram colhidos de uma população de plantas, onde a possibilidade de uniformidade na maturação da semente é pequena. Esse efeito pode ser observado pela diferença no crescimento das plântulas, no momento da realização da primeira contagem do teste de germinação (20 dias) e na contagem final das sementes, aos 40 dias do início do teste (Figuras 4 e 5).

Os colhedores de sempre-viva, em Diamantina, realizam
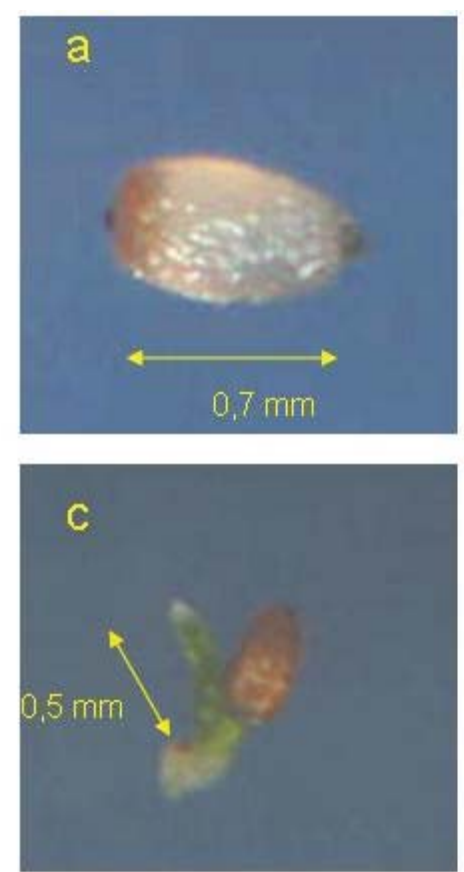

a colheita dos escapos florais, nos meses de março a abril e, após os trabalhos de secagem, limpeza e seleção para exportação, o material descartado (varredura), constituído de escapos, capítulos pequenos e com defeitos, é armazenado no próprio armazém para semeadura na época das águas. Os resultados encontrados no presente trabalho, portanto, confirmam a melhoria da qualidade fisiológica da semente de S. elegans quando armazenada para posterior semeadura, em época favorável.
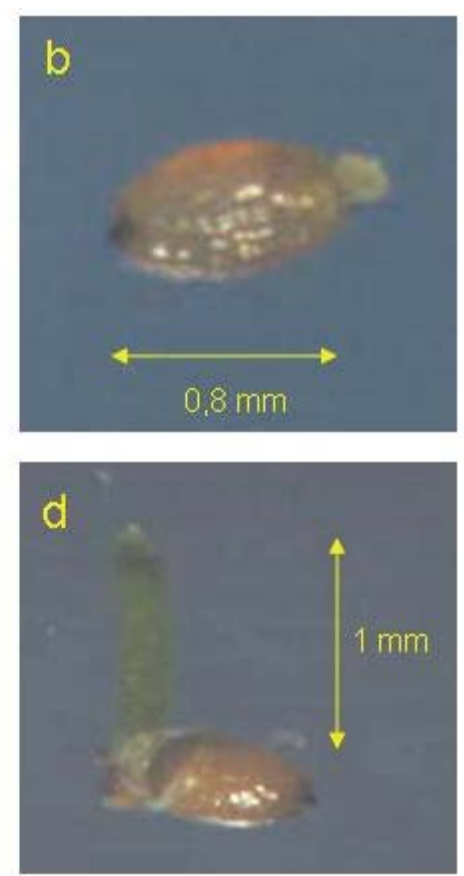

FIGURA 4. Semente de Syngonanthus elegans (Bong.) Ruhland aos 10 dias, não germinada (a) e início de germinação (b) e aos 20 dias (c e d) após o início do teste.
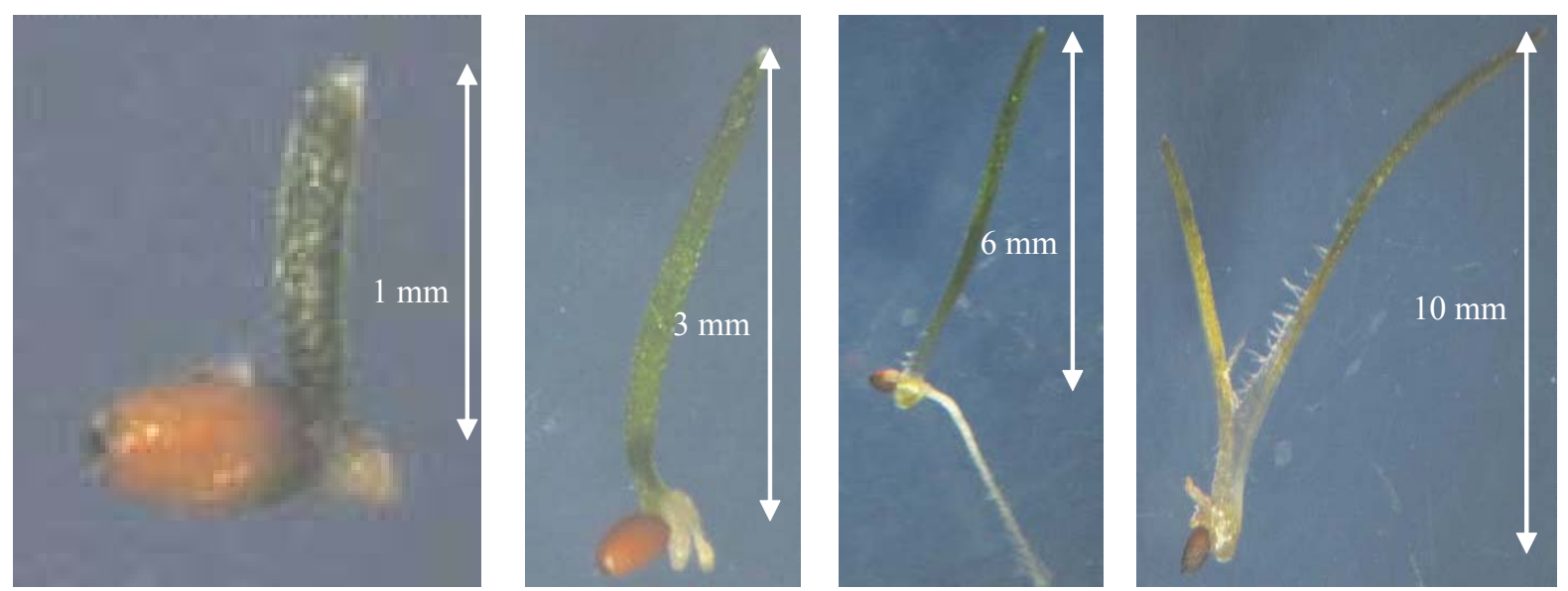

FIGURA 5. Sementes e plântulas de Syngonanthus elegans (Bong.) Ruhland aos 40 dias após início do teste de germinação. 


\section{CONCLUSÕES}

A qualidade fisiológica da semente de $S$. elegans varia em função da época e do local de colheita.

$\mathrm{O}$ armazenamento por 12 meses em geladeira ou temperatura ambiente melhora a qualidade fisiológica da semente proveniente de diferentes locais de coleta.

\section{REFERÊNCIAS}

AGUIAR, I.B. Conservação de sementes. In: SILVA, A; PINA-RODRIGUES, F.C.M, FIGLIOLIA, M.B. Manual técnico de sementes florestais. São Paulo: Instituto Florestal, 1995. p.33-44. (Série Registros, 14).

BEDÊ, L.C. Busca de alternativas para uso sustentado de sempre-vivas na região de Diamantina, MG: estudo dos efeitos decorrentes do manejo extrativista sobre a dinâmica populacional de Syngonanthus elegans var. elenatus (Eriocaulaceae). In: RELATÓRIO TÉCNICO. Belo Horizonte: Instituto de Ciências Biológicas, UFMG, 2002. 17p.

BEWLEY, J.D. \& BLACK, M. Seeds physiology of development and germinatiton. New York: Plenum Press, 1985. 367p

BIANCHETTI, A. Tecnologia de sementes de essências florestais. Revista Brasileira de Sementes, Brasília, v.3, n.3, p.27-46, 1981.

CARNEIRO, J.G.A; AGUIAR, I.B. Armazenamento de sementes. In: AGUIAR, I.B. PINA-RODRIGUES, F.C.M, FIGLIOLIA, M.B. Sementes Florestais Tropicais. Brasília: ABRATES, 1993. p.333-350.

EMBRAPA. Centro Nacional de Pesquisas de Solos. Sistema Brasileiro de Classificação de Solos. Rio de Janeiro: Embrapa Solos, 2006. 306p.

GIULIETTI, N.; GIULIETTI, A.M.; PIRANI， J.R.; MENEZES, N.L. Estudos de sempre-vivas: importância econômica do extrativismo em Minas Gerais, Brasil. Acta Botanica Brasílica, São Paulo, v.1, n.2, p.179-192, 1988.

INMET - INSTITUTO NACIONAL DE METEOROLOGIA. Disponível em: <http://www.inmet.gov.br>. Acesso em: 20 abr. 2006.

KLIPS, A.R.; PENÃLOSA, J. The timing of seed fall, innate dormancy, and ambient temperature in Lythrum salicaria. Aquatic Botany, Amsterdam, v.75, n.1, p.1-7, 2003.
KRAUS, J.E; SCATENA, V.L.; LEWINGER, M.E.; TRENCH, K.U.Morfologia externa e interna de quatro espécies de Paepalanthus Kunth (Eriocaulaceae) em desenvolvimento pós-seminal. Boletim de Botânica da Universidade de São Paulo, São Paulo, v.15, n.1, p.45-53, 1996.

MENDONÇA, M.P.; LINS, L.V. Lista vermelha das espécies ameaçadas de extinção da flora de Minas Gerais. Belo Horizonte: Fundação Biodiversitas/Fundação ZooBotânica de Belo Horizonte, 2000. 157p.

NAKAGAWA, J.; CAVARIANI, C.; FELTRAN, J.C. \& OLIVEIRA, R.L. Maturação de sementes de azevém-anual (Lolium multiflorum Lam.). Revista Brasileira de Sementes, Brasília, v.21, n.1, p.174-182, 1999.

OLIVEIRA, P.G.; GARCIA, Q.S. Efeitos da luz e da temperatura na germinação de sementes de Syngonanthus elegantulus Ruhland, S. elegans (Bong.) Ruhland e $S$. venustus Silveira (Eriocaulaceae). Acta Botanica Brasílica, São Paulo, v.19, n.3, p.639-645, 2005.

PAIXÃO-SANTOS, J.; DORNELLES, A.L.C; SILVA, J.R.S.; RIOS, A.P. Germinação in vitro de Syngonanthus mucugensis Giulietti. Sitientibus série Ciência Biológicas, Feira de Santana, v.3, n.1/2, p.120-124, 2003.

PARRA, J.R. Flora da Serra do Cipó, Minas Gerais: Syngonanthus Ruhland (Eriocaulaceae). Boletim de Botânica da Universidade de São Paulo, São Paulo, v.17, p.219-252, 1998.

POPINIGIS, F. Fisiologia da semente. Brasília: AGIPLAN, 1977. 298p.

SÁ CARVALHO, C.G.; RIBEIRO, M.C. Efeitos do armazenamento e de reguladores de crescimento na germinação de Paepalanthus speciosus, Eriocaulaceae. Revista Brasileira de Botânica, São Paulo, v.17, n.1, p.61-65, 1994.

SCATENA, V.L.; CARDOSO, V.A.; GIULIETTI, A.M. Morfoanatomia de espécies de Blastocaulon Ruhland (Eriocaulaceae). Acta Botanica Brasílica, São Paulo, v.13, n.1, p.29-41, 1999.

SCATENA, V.L.; LEMOS FILHO, J.P.; LIMA, A.A.A. Morfologia do desenvolvimento pós-seminal de Syngonanthus elegans e S. niveus (Eriocaulaceae). Acta Botanica Brasílica, São Paulo, v.10, n.1, p.85-91, 1996.

TOLE, V.K. Effects of light, temperature and their interactions on germination of seeds. Seed Science \& Tecnology, Zürich, v.1, n.2, p.339-396, 1973. 